\title{
Pengintegrasian Pendidikan Islam dengan Pendidikan Alam Sekitar di Sekolah: Analisis Terhadap Adaptasi Pendekatan Integrasi Kurikulum Holistik ${ }^{1}$
}

\author{
Abd Aziz Rekan \\ Universiti Malaya, abdazizrkn@um.edu.my \\ Tengku Sarina Aini Tengku Kasim \\ Universiti Malaya, tgsarina@um.edu.my \\ Yusmini Md Yusoff \\ Universiti Malaya,yusmini@um.edu.my
}

\begin{abstract}
Abstrak
Pengintegrasian nilai-nilai agama dengan komponen alam sekitar dalam sistem pendidikan di sekolah merupakan antara penyumbang terhadap pembangunan masyarakat lestari. Seseorang individu bukan sahaja dibangunkan dari aspek pengetahuan, kemahiran dan sikap positif terhadap alam sekitar, bahkan usaha tersebut perlu diperkukuhkan dengan penerapan nilai-nilai ketuhanan agar memahami fungsinya sebagai hamba dan khalifah Allah. Justeru, Artikel ini mengetengahkan idea konseptual mengenai aplikasi pendekatan integrasi kurikulum holistik terhadap pengintegrasian pendidikan alam sekitar dengan pendidikan Islam di sekolah. Hasil analisis memaparkan bahawa pendekatan integrasi kurikulum secara teknikal yang dibawa oleh Robin Fogarty adalah menepati prinsip dan roh Islam dalam menyepadukan pelbagai ilmu dalam sistem pendidikan di sekolah. Nilai eko-etika Islam dilihat bukan sahaja dapat diketengahkan secara komprehensif bahkan bersepadu dengan elemen saintifik dan disiplin ilmu lain berdasarkan adaptasi pendekatan tersebut. Cadangan adaptasi model ini diharapkan dapat membantu para guru dalam membangunkan pengetahuan kandungan pedagogi integrasi kurikulum di sekolah sama ada secara formal mahupun tidak formal.
\end{abstract}

Kata kunci: etika alam sekitar, pendidikan Islam, pendidikan alam sekitar, integrasi kurikulum holistik

1 Artikel ini telah dibangunkan dan dimurnikan daripada makalah yang telah dibentangkan dalam $2^{\text {nd }}$ International Conference on Arabic Studies \& Islamic Civilization (iCASiC2015) pada 9-10 Mac 2015 bertempat di Melia Hotel, Kuala Lumpur. 


\title{
Integrating Islamic Education with Environmental Education in School: An Analysis on the Adaptation of Integration Approach of Holistic Curriculum
}

\begin{abstract}
The integration of Islamic values with the environmental component in the education system is an important contribution for development of sustainable society. An individual is not only being developed their knowledge, skills and positive attitude towards the environment, but also to strengthen and instil the divine values to be suited to the role as servant and caliph of Allah. Therefore, this article focuses on the conceptual idea on the implementation of holistic curriculum towards the integration of environmental education and Islamic education in school. The analysis of the findings indicates that the approach of holistic curriculum by Robin Fogarty complies with the principle and Islamic values through the integration of various disciplines of knowledge in educational system. This approach is not only bringing the eco-ethical values of Islam comprehensively but also integrating the scientific knowledge and other disciplines. The proposal to adopt this approach is expected to assist teachers in developing pedagogical content knowledge for holistic curriculum whether formal or non-formal education in school context.
\end{abstract}

Keywords: environmental ethics, Islamic education, environmental education, integration of holistic curriculum

\section{Pendahuluan}

Ketelusan dan budi pekerti manusia terhadap kelestarian alam sekitar seringkali dipersoalkan. Saban hari entiti ini seumpama alpa mentradisikan gaya hidup teosentrik ${ }^{2}$. Walaupun begitu, pelbagai usaha telah dilakukan sama ada daripada lapisan "topdown" mahupun "bottom-up" bagi menyedarkan ahli masyarakat akan tanggungjawab mereka terhadap alam sekitar ${ }^{3}$. Antara isu

2 Istilah teosentrik merujuk kepada pemusatan nilai ketuhanan terhadap pemeliharaan alam sekitar yang menekankan kesatuan hubungan manusia dengan tuhan serta ciptaanNya termasuklah alam sekitar.

3 Ahmad Firdaus Dzulkarnain, "Masa Untuk Sukarelawan Berbakti Bantu Mangsa Banjir", Utusan Malaysia Online, 30 Disember 2014, dicapai pada 15 Januari 2015, http://www.utusan.com.my/rencana/masa-untuk-sukarelawanberbakti-8232-bantu-mangsa-banjir-1.42463; Roskhoirah Yahya, "Misi Kumpulan Utusan ke Kuala Krai”, Utusan Malaysia Oline, 21 Januari 2015, diakses pada 2 Februari 2015, http://www.utusan.com.my/berita/nasional/misikumpulan-utusan-ke-kuala-krai-1.50406. 
yang hangat diperdebatkan di seantero dunia bagi melestarikan keharmonian bumi ialah cabaran memperkasakan penghayatan agama dan nilai etika alam sekitar dalam kalangan manusia ${ }^{4}$. Mendasari realiti ini, satu kajian dari sudut pendidikan telah dilakukan oleh Hazura Ab Bakar (2009) yang mendapati bahawa terdapat hubungan yang positif dan signifikan bagi penghayatan agama dengan sikap $(\mathrm{r}=0.279, \mathrm{p}<0.01)$ dan tingkah laku $(\mathrm{r}=0.386$, $\mathrm{p}<0.01)$ pelajar Muslim terhadap alam sekitar di Malaysia 5 . Maksudnya penghayatan agama merupakan antara faktor penyumbang bagi mewujudkan pelajar yang berekoliterasi atau celik alam sekitar.

Melihat kepada sistem pendidikan di Malaysia, seolah-olah terdapat kelompongan dalam pendekatan menyepadukan nilai keagamaan dengan nilai alam sekitar untuk diintegrasikan dalam proses pengajaran dan pembelajaran di sekolah. Berdasarkan dapatan kajian Maria dan Hazinah (2009), seramai 10.6\% guru pendidikan Islam daripada 613 orang guru-guru sekolah menengah yang merupakan sampel kajian di sekitar negeri Perak, Selangor dan Wilayah Persekutuan tidak pasti tentang penerapan Pendidikan Alam Sekitar merentas kurikulum ${ }^{6}$. Justeru itu, artikel ini akan cuba menganalisis secara konseptual beberapa pendekatan integrasi kurikulum holistik yang terpilih sebagai panduan alternatif kepada para guru pendidikan Islam dalam mengintegrasikan pengajaran dan pembelajaran pendidikan Islam dengan pendidikan alam sekitar di sekolah.

Metodologi penulisan konseptual ini adalah berdasarkan adaptasi pendekatan kajian dokumentasi. Pelbagai sumber rujukan

4 Fachruddin Majeri Mangunjaya, "Developing Environmental Awareness and Conservation through Islamic Teaching," Journal of Islamic Studies 22, no. 1 (2011): 36-49; Najma Mohamed, Revitalising an Eco-Justice Ethics of Islam: by Way of Environmental Education: Implications for Islamic Education (tesis kedoktoran, South Africa, Stellenbosch University, 2012), 56-145; A. M. Schwencke, Globalized Eco-Islam: A Survey of Global Islamic Environmentalism (Leiden University: Leiden Institute for Religious Studies (LIRS), 2012), 20-43.

5 Hazura Abu Bakar, "Hubungan Antara Penghayatan Agama, Nilai Hidup dan Pengetahuan Alam Sekitar Pelajar Muslim degan Sikap dan Tingkah Laku”, (tesis kedoktoran, Universiti Sains Malaysia, 2009).

6 Maria Salih dan Hazinah Nor Hanipah. Penerapan Pendidikan Alam Sekitar Merentas Kurikulum di Kalangan Guru Sekolah Menengah: Satu Tinjauan, laporan akhir penyelidikan (Universiti Pendidikan Sultan Idris, 2009), 34-55. 
telah dianalisis dan disintesis secara induktif mahupun deduktif yang antaranya daripada buku, artikel, tesis, laporan rasmi, kertas persidangan atau seminar dan laporan akhbar. Kaedah tematik juga turut diaplikasikan dalam menganalisis sumber-sumber tersebut bagi memastikan bersesuaian dengan kandungan konsep artikel yang dibincangkan. Selain itu, perisian Mendeley 1.16.1 antara perisian yang digunakan dalam mengaturcarakan sumber rujukan tersebut secara sistematik dan pencarian sumber secara menyeluruh di samping bantuan online database yang dibekalkan oleh pihak Universiti Malaya.

Walau bagaimanapun, pada zaman yang serba canggih ini terdapat pelbagai perisian seperti Atlas.ti dan juga Nvivo yang boleh membantu dan memudahkan para penyelidik dalam menyoroti perbincangan dan perdebatan ahli akademik mengenai sesuatu konsep atau isu sesuatu bidang disiplin ilmu menerusi beberapa sumber rujukan semasa. Berbekalkan pengetahuan dan kemahiran yang cukup dalam Teknologi Maklumat dan Komunikasi (TMK), para penyelidik berupaya menghasilkan dan menyediakan sesuatu penulisan akademik yang komprehensif dan tersusun berdasarkan konteks kajian yang dijalankan ${ }^{7}$. Maka dalam konteks artikel ini, kupasan konseptual mengenai pengintegrasian pendidikan Islam dan alam sekitar akan dibahasakan secara terperinci dalam penulisan seterusnya.

\section{Pemerkasaan Nilai Etika Alam Sekitar dalam Pendidikan Islam Di Sekolah}

Abedi-Sarvestani, Shahvali dan Mohaghegh-Damad (2007) mengutarakan dua persoalan dan respon bagi mengkonsepsikan etika alam sekitar menurut perspektif Islam. Pertama, apakah nilai intrinsik yang perlu dimiliki bagi melayani alam sekitar?, dan kedua, apakah kriteria yang diperlukan bagi menilai tingkah laku individu (nilai ekstrinsik) sebagai refleksi moralnya terhadap alam sekitar?. Maka respon yang dicadangkan oleh mereka bagi soalan pertama ialah perlu ada aspek aksiologi iaitu nilai ketuhanan dalam diri individu. Ini adalah kerana segala apa yang ada di alam semesta ini adalah ciptaan tuhan maka berhak dilayani

7 Othman Talib, Zero Draft of Thesis: Teknik Efisien Penulisan Tesis dengan Navigation Pane/Document Map dan Mandeley (Selangor: MPWS Rich Resources, 2014), 2-35. 
berdasarkan pertimbangan etika. Respon seterusnya ialah perlu ada kriteria etika deontologi ${ }^{8}$ iaitu tanggungjawab melaksanakan perintah tuhan bagi memakmurkan alam sekitar'. Konsep yang diketengahkan ini memaparkan kemurnian hubungan secara vertikal; iaitu antara tuhan dengan manusia, secara horizontal; antara manusia dengan manusia dan secara triangulasi; antara tuhan dengan manusia dan alam sekitar.

Oleh yang demikian, kelestarian ketiga-tiga hubungan itu adalah didasari oleh prinsip dan konsep asas eko-teologi Islam. Adapun para sarjana Islam telah mengekstrak prinsip-prinsip tersebut berlandaskan al-Quran dan al-Hadis di samping mengambil kira pandangan para ulama sebagai perincian terhadap konteks semasa. Antara prinsip dan konsep eko-teologi adalah tauhid, pencipta (khaliq) dan penciptaan (sunan al-kawn), khalifah, kehambaan ('ubudiyyah), ihsan, fitrah, ketakwaan, kebaikan (hasanah), kerosakan (fasad), dosa dan pahala, ekulibrium (tawazun) dan simetri (mizan), kesederhanaan (wasatiyyah), merasa cukup (qana'ah), kerjasama (ta'wun), tamak (takahtur) dan pembaziran (israf/tadbhir) ${ }^{10}$. Sehingga abad ini dilihat manifestasi nilai-nilai tersebut hampir berjaya diglobalisasikan menerusi pendekatan-pendekatan yang fleksibel

8 Etika deontologi merujuk kepada wujudnya pertimbangan secara intrinsik terhadap sesuatu tindakan, amalan, perlakuan atau peraturan yang dianggap baik, benar dan diwajibkan.

9 A. Abedi-Sarvestani, et al., "Essence and outlooks of environmental ethics with emphasis on Islamic perspective," Iranian Journal of Ethics in Science and Technology 2, no. 1 (2007): 59-72.

${ }^{10}$ Mohd Istajib Mokhtar \& Raihanah Abdullah, "Islamic Environmental Jurisprudence and Conservation Practices in Malaysia", Journal of Dharma 39, no. 2 (2014): 7-22; Ekpenyong Obo Ekpenyong,. "Islam and Global Ecological Crisis: An Eco-Theological Review", International Journal of Asian Social Science 7, no. 3 (2013): 591-1594; Ibrahim Abu Bakar, "Islamic Theological Teachings on Ecology", International Journal of Business and Social Science 3, no. 13 (July 2012): 222-226; Fachruddin Majeri Mangunjaya, "Developing Environmental Awareness and Conservation through Islamic Teaching," Journal of Islamic Studies 22, no. 22 (2011): 36-49; Najma Mohamed, Revitalising an Eco-Justice Ethics of Islam: by Way of Environmental Education: Implications for Islamic Education, 86-131; S.H. Nasr, Man and Nature: the Spiritual Crisis of Modern Man (New Edition Chicago, ABC International Group, 1997); S.H. Nasr, Religion and the Order of Nature (New York Oxford: Oxford University Press, 1996). 
sebagai kandungan didikan dalam memelihara dan memulihara alam sekitar ${ }^{11}$.

Menelusuri sistem pendidikan di Malaysia yang berorientasikan Falsafah Pendidikan Kebangsaan dan Falsafah Pendidikan Islam, nilai-nilai etika alam sekitar menurut lensa Islam ini disarankan untuk dijelmakan dalam proses pengajaran dan pembelajaran di sekolah. Penekanan kepada pembangunan modal insan yang seimbang dari segenap aspek berdasarkan kepercayaan dan kepatuhan kepada tuhan merupakan antara agenda utama Pelan Pembangunan Pendidikan Negara (PPPM) 2013-2025 $5^{12}$, bahkan ianya juga adalah antara punca kuasa bagi memperkasakan nilai eko-etika Islam dalam kalangan pelajar Muslim di sekolah. Oleh demikian, sebagai sebuah negara yang mendeklarasikan Islam sebagai agama rasmi, matapelajaran pendidikan Islam yang wajib dipelajari oleh pelajar Muslim di sekolah rendah mahupun menengah merupakan subjek yang telah digazetkan dalam kurikulum kebangsaan bagi memastikan golongan Muslim memperolehi dan membangunkan pengetahuan, kemahiran dan nilai selari dengan tuntutan Islam.

Kurikulum pendidikan Islam adalah meliputi aspek pemahaman, penghayatan dan pengaplikasian terhadap al-Quran, Hadis, akidah, adab dan akhlak, ibadah dan sirah nabawiyyah sebagai asas panduan hidup. Merefleksi kembali intisari kurikulum pendidikan Islam di sekolah, banyak memaparkan bahawa kehidupan sebagai seorang Muslim adalah berkait rapat dengan elemen alam sekitar. Umat Islam seharusnya memiliki dan menghayati nilai eko-etika Islam bagi menjamin kelestarian futuristik alam sekitar menerusi sikap positif dan tindakan proekologi seperti berakhlak mulia dalam memperlakukan manusia, binatang, tumbuh-tumbuhan, air, tanah dan lain-lain dengan baik dan saksama. Hal ini selaras dengan pendapat Zaini Ujang yang menegaskan bahawa adalah satu kewajipan dan tanggungjawab

${ }^{11}$ A. M. Schwencke, Globalized Eco-Islam: A Survey of Global Islamic Environmentalism, 23-54.

12 Kementerian Pendidikan Malaysia, Pelan Pembangunan Pendidikan Malaysia 2013-2025: Pendidikan Prasekolah hingga Lepas Menengah (Putrajaya: Kementerian Pendidikan Malaysia, 2013), 15-16. 
kepada manusia untuk melestarikan alam sekitar tanpa ada unsur pilihan bagi melepaskan diri daripada taklifan tersebut ${ }^{13}$.

Kewujudan mata pelajaran pendidikan Islam di sekolah mampu mencetuskan pengalaman penerapan ekologi spritual dan nilai etika Islam secara langsung dalam kalangan pelajar. Melihat dari aspek ekologi spiritual iaitu rukun Islam yang terkandung dalam silibus, rukun Islam yang pertama merujuk kepada pengakuan Allah SWT sebagai tuhan yang maha esa dan Nabi Muhammad S.AW adalah pesuruh Allah SWT merupakan janji manusia untuk melaksanakan perintahNya dan meninggalkan laranganNya termasuklah dalam mengharmonikan alam sekitar. Rukun Islam seterusnya iaitu menunaikan solat merupakan amalan spiritual dalam mengabdikan diri kepada Allah. Komponen air sebagai alat untuk berwuduk merupakan syarat pelaksanaan solat dan debu tanah untuk bertayammum sebagai ganti jika ketiadaan air. Ibadat haji pula, diharamkan kepada Jemaah haji untuk berburu binatang semasa dalam ihram.

Manakala Ibadat puasa, seseorang Muslim perlu membuat atau membeli juadah berbuka puasa dengan kadar yang sepatutnya bagi mengelakkan pembaziran. Sekiranya juadah yang berlebihan tidak diurus dengan baik maka akan menyumbang kepada peningkatan kos pengurusan pembuangan sisa pepejal. Sedangkan kos pengurusan tersebut boleh digunakan untuk perihal lain dan yang lebih utama oleh pihak berkuasa tempatan dalam membangunkan infrastruktur serta menceriakan kawasan setempat. Seterusnya pelaksanaan ibadat zakat, diperintahkan kepada umat Islam untuk membayar zakat dengan kadar yang ditentukan berdasarkan sesuatu tempat di samping tuntutan pelaksanaan zakat pertanian seperti daripada hasil ternakan haiwan dan kutipan buah-buahan atau sayuran di ladang. Betapa akrabnya elemen alam sekitar dalam kandungan matapelajaran pendidikan Islam sama ada secara tersurat mahupun tersirat. Kandungannya dari sekecil-kecil benda hidup sehinggalah benda bukan hidup yang mungkin dianggap biasa akan tetapi memerlukan komitmen yang lebih untuk disebatikan penghayatan dalam diri guru dan juga pelajar.

${ }^{13}$ Zaini Ujang, Minda Lestari: Pembangunan Negara dan Pemuliharaan Alam Sekitar (Johor Bahru: UTM Press, 2009) 
Oleh yang demikian, penyepaduan pendidikan alam sekitar dengan pendidikan Islam di sekolah dilihat antara mekanisme yang berperanan penting dalam memacu pembangunan lestari dan kemampanan negara. Menerusi penyepaduan ini, pendedahan disiplin ilmu secara holistik kepada para pelajar tanpa memisahkan komponen alam sekitar dengan agama akan menggalakkan mereka untuk menghayati gaya hidup Islami sekaligus ke arah mencetuskan insan Rabbani yang celik alam sekitar. Justeru itu, bagi merealisasikan hasrat ini, penggemblengan tenaga dan usaha sama guru pendidikan Islam dengan guru-guru yang lain di sekolah adalah perlu dalam menggerakkan proses pengintegrasian kedua-dua pendidikan tersebut secara ampuh.

\section{Agenda Pendidikan Alam Sekitar Merentas Kurikulum Pendidikan Islam}

Pendidikan alam sekitar merupakan medium yang wajar diaplikasikan bagi menyalurkan maklumat, mengembangkan kemahiran, menggalakkan penyertaan dan merangsang tindakan positif terhadap biodiversity ${ }^{14}$. Medium ini diaplikasikan semenjak tahun 1977 lagi selepas Persidangan Tiblisi dilangsungkan bagi memastikan setiap warganegara memperolehi manfaat untuk menjalani kehidupan buat masa kini dan akan datang. Secara umumnya, pendidikan alam sekitar menekankan enam domain utama ke atas isu-isu alam sekitar iaitu kesedaran, pengetahuan, sikap, kemahiran, keupayaan menilai dan penyertaan ${ }^{15}$.

Menurut Najma (2012), Helen dan Frans, (2014), tiga pendekatan asas bagi merealisasikan domain-domain ini iaitu pertama, pendidikan "tentang" alam sekitar yang memfokuskan peranan kognitif, kemahiran dan kefahaman untuk bertindak positif terhadap alam sekitar. Kedua, pendidikan "melalui" alam sekitar yang mengutamakan elemen alam sekitar dijadikan sebagai alat atau medium langsung mencetuskan kesedaran dan sikap yang seharusnya. Ketiga, pendidikan"untuk"alam sekitar yang menekankan keupayaan menilai dan keterlibatan individu secara

\footnotetext{
${ }^{14}$ Nurul Hidayah et al.,"Pengetahuan Murid dan Perkaitan Ibu Bapa Terhadap Kesedaran Alam," Jurnal Teknologi 1 (2013): 51-57.

${ }^{15}$ Helen Kopnina \& Frans Meijers, "Education for Sustainable Development (ESD)", International Journal of Sustainability in Higher Education 15, no. 2 (2014): 188-207.
} 
konsisten dalam menangani isu dan penyelesaian masalah alam sekitar $^{16}$.

Sejarah pendidikan alam sekitar mula diperkenalkan rentetan daripada Persidangan Manusia dan Alam Sekitar di Stockholm pada 1972 yang menitikberatkan hubungan antara sikap dan tingkahlaku manusia dengan alam sekitar ${ }^{17}$. Solusi persidangan ini menuntut agar semua negara perlu mewujudkan kapasiti serta ruang pendidikan kepada rakyatnya berkaitan pemeliharaan dan pemuliharaan alam sekitar termasuklah Malaysia. Usaha awal kerajaan Malaysia bagi mewujudkan rakyat yang sedar dan peka terhadap isu alam sekitar menerusi pendidikan alam sekitar telah disyorkan dalam tempoh Rancangan Malaysia ketiga (1976$1980)^{18}$. Semenjak daripada itu, kurikulum pendidikan di Malaysia mengalami transformasi dengan wujudnya Kurikulum Bersepadu Sekolah Rendah (KBSR) dan Kurikulum Bersepadu Sekolah Menengah (KBSM) yang ingin menyepadukan pendidikan alam sekitar dalam sukatan pelajaran sekolah.

Sehubungan itu, pada tahun 1982, Pendidikan alam sekitar merentasi kurikulum mula dirintiskan di 305 buah sekolah rendah dan seterusnya dilaksanakan di kesemua sekolah rendah pada tahun $1983^{19}$. Pada tahun 1986, pendidikan alam sekitar merentasi kurikulum yang berasaskan sains sehinggalah yang berunsurkan agama Islam telah diperkenalkan di keseluruhan sekolah rendah dan menengah di Malaysia ${ }^{20}$. Pada penghujung tahun 1986, mata pelajaran khas iaitu Alam dan Manusia secara rasmi diperkenalkan sebagai mata pelajaran dalam kurikulum sekolah rendah tahap 2 iaitu tahun 4, 5 dan 6. Mata pelajaran tersebut meliputi unsurunsur ilmu pengetahuan, sains kesihatan, geografi, sejarah, sains

${ }^{16}$ Helen Kopnina dan Frans Meijers, "Education for Sustainable Development (ESD)", 188-207.

${ }^{17}$ Habibah Lateh \& Punitha Muniandy. "Amalan Pengajaran Pendidikan Alam Sekitar Di Institut Pendidikan Guru, Kampus Pulau Pinang,” Malaysia Journal of Society and Space 2, no. 2 (2012):1-6.

${ }^{18}$ M. S. Aini et al., "Impact of Environmental Education on Concern, Knowledge and Sustainable Behavior of Primary School Children", Health and the Environment Journal 2, no. 1 (2011). 50-53.

${ }^{19}$ M. S. Aini et al., "Impact of Environmental Education on Concern, Knowledge and Sustainable Behavior of Primary School Children, 50-53.

${ }^{20}$ M. S. Aini et al., "Impact of Environmental Education on Concern, Knowledge and Sustainable Behavior of Primary School Children, 50-53. 
sosial dan $\operatorname{sivik}^{21}$. Di peringkat sekolah menengah, elemen alam sekitar difokuskan dalam subjek berasingan iaitu geografi dan sains. Sekitar tahun 1995, mata pelajaran Manusia dan Alam Sekitar dimansuhkan kerana matlamat yang digariskan dalam mata pelajaran ini tidak tercapai ${ }^{22}$.

Walau bagaimanapun, pendidikan alam sekitar hampir disepadukan dalam semua mata pelajaran di peringkat sekolah rendah dan menengah bermula pada tahun 1998 termasuklah subjek Pendidikan Islam. Pada tahun 1998 ini juga terbitnya Buku Panduan Guru Pendidikan Alam Sekitar merentas Kurikulum untuk sekolah rendah dan menengah oleh Bahagian Pembangunan Kurikulum (BPK) Kementerian Pelajaran Malaysia (KPM). Manakala peringkat prasekolah pula buku tersebut telah diterbitkan pada tahun $2005^{23}$.

Terdapat enam komponen utama dalam buku panduan tersebut yang perlu dititkberatkan oleh setiap guru dalam menyepadukan pendidikan alam sekitar dengan subjek yang diajar termasuklah pendidikan Islam. Komponen-komponen tersebut adalah tuhan pencipta alam semesta dan sekalian makhluk, bumi dan alam semesta, benda hidup dan semulajadi, benda hidup dan alam sekitar, interaksi manusia, haiwan dan tumbuhan serta akhir sekali pengurusan alam sekitar ${ }^{24}$.

Pada dasarnya, pendidikan alam sekitar dilaksanakan dalam bentuk formal mahupun tidak formal. Pendidikan formal melibatkan kelangsungan pendidikan alam sekitar di peringkat sekolah rendah dan menengah yang tertakluk dengan peraturan, pekeliling dan pemantauan Kementerian Pelajaran Malaysia $(\mathrm{KPM})^{25}$. Pendidikan secara formal merangkumi pengisian

${ }^{21}$ Nurul Hidayah et al., "Pengetahuan Murid dan Perkaitan Ibu Bapa Terhadap Kesedaran Alam, 51-57.

${ }^{22}$ M. S. Aini et. al, "Impact of Environmental Education on Concern, Knowledge and Sustainable Behavior of Primary School Children, 50-53.

${ }^{23}$ Ho Yuek Ming \& Azizi Muda, Assessment of Pre-Service Teachers' Environmental Citizenship Attributes: Implications for Environmental Education Curriculum and Training (3rd International Conference on Science and Mathematics Education (COSMEd), Pulau Pinang, 2009), 1-5.

${ }^{24}$ Pusat Perkembangan Kurikulum, Buku Panduan Guru Pendidikan Alam Sekitar Merentas Kurikulum KBSM (Pusat Perkembangan Kurikulum, Kementerian Pendidikan Malaysia, 1999), 4-10.

${ }^{25}$ Zarrintaj Aminrad et al., "Environmental Education in Malaysia, Progresses and Challenges Ahead", Life Science Journal 9, no. 2 (2012): 1149-1154. 
kurikulum berbentuk akademik dan kokurikulum dalam bentuk aktiviti dan program anjuran sekolah. Manakala pendidikan tidak formal pula berlangsung di luar institusi sekolah iaitu pendidikan alam sekitar lebih difokuskan kepada komuniti masyarakat.

\section{Analisis Pendekatan Integrasi Kurikulum Pendidikan Islam dengan Pendidkan Alam Sekitar di Sekolah}

Khazanah ilmu yang diwarisi sehingga sekarang sama ada secara epistemologi, ontologi dan aksiologi adalah ilmu yang bersumberkan wahyu al-Quran dan al-Hadis. Yahaya Jusoh dan Azhar Muhammad, antara yang telah membahaskan secara terperinci pendidikan falsafah sains al-Quran dengan mengkategorikan ilmu alam sekitar dalam perbincangan ilmu sains natural (natural science) yang juga saling berkait rapat dengan sains ketuhanan (divine science) dan sains sosial (social science) ${ }^{26}$. Dalam erti kata lain, sesuatu hikmah ilmu tidak akan terpisah antara satu sama lain tidak kira sama ada berkaitan sains dan teknologi, sosiologi atau biologi yang tetap diikat dengan ilmu ketuhanan dan inilah yang dikatakan kesepaduan ilmu atau kurikulum holistik bagi pendidikan umat Islam. Berdasarkan pandangan harmoni ini jelaslah bahawa konsep kesepaduan pendidikan Islam dengan pendidikan alam sekitar di sekolah adalah untuk mengenal kewujudan Tuhan tanpa memisahkan bukti-bukti kebesaranNya ke arah membina tamadun rabbaniyyah dan syamilah ${ }^{27}$.

Konotasi integrasi adalah sinonim dengan perkataan bersepadu, bergabung dan berpadu ${ }^{28}$. Terminologi integrasi kurikulum kerap kali digunakan oleh pakar bidang pendidikan kurikulum seperti Drake, Fogarty, dan Jacobs, dalam menjelaskan konsep kurikulum bersepadu ${ }^{29}$. Manakala Vars pula menggunakan

${ }^{26}$ Yahaya Jusoh dan Azhar Muhammad, Pendidikan Falsafah Sains Al-Quran (Skudai: Universiti Teknologi Malaysia, 2007), 19-177.

27 Yahaya Jusoh \& Azhar Muhammad, Falsafah Ilmu dalam Al-Quran: Ontologi, Epistemologi dan Aksiologi (Skudai: Universiti Teknologi Malaysia, 2012), 3.

${ }^{28}$ Laman Sesawang Dewan Bahasa dan Pustaka, dicapai pada 2 Januari 2015, http://prpm.dbp.gov.my/Search.aspx?k=integrasi.

${ }^{29}$ S. Drake, Planning Integrated Curriculum: The Call to Adventure (Alexandria: Association for Supervision and Curriculum Development, 1993), t.h.; R. Fogarty, The Mindful School: How to Integrate the Curriculum. Pallantine, (Skylight Publishing, IL, 1991a); H. Jacobs, (ed.), Interdisciplinary 
istilah korelasi dan gabungan dalam menghubungkan disiplindisiplin ilmu dalam kurikulum pendidikan ${ }^{30}$. Walau bagaimanapun, pengistilahan integrasi kurikulum telah melahirkan pelbagai perspektif dari segi definisi, teori dan model dalam kalangan sarjana barat ${ }^{31}$. Marcella merupakan antara yang telah merangkumkan penginterpretasian integrasi kurikulum dengan menyatakan bahawa integrasi kurikulum ataupun kurikulum bersepadu akan mewujudkan penyertaan guru dan pelajar secara aktif bagi memastikan keberkesanan pembelajaran yang bermakna $^{32}$. Selain itu, integrasi kurikulum perlu melibatkan aktiviti pembelajaran yang interaktif di samping penggunaan teknologi maklumat dan komunikasi bagi menarik minat pelajar. Konsep ilmu bukan bersifat statik bahkan berkembang pesat serta diaplikasikan secara integratif mengikut realiti semasa, bukan terpisah antara satu sama lain ${ }^{33}$.

Dari sisi perspektif Islam pula, International Institute of Islamic Thought (IIIT), telah mengetengahkan lima ciri kurikulum bersepadu iaitu; 1) bidang-bidang antara mata pelajaran saling berhubungan; 2) kesepaduan antara teori dan amalan; 3) pengalaman dalam kelas dihubungkan dengan pengalaman luar kelas; 4) penerapan nilai-nilai murni merentasi kurikulum dan yang terakhir; 5) pelestarian insan kamil dari segenap aspek seperti rohani, intelek, imaginasi, emosi dan fizikal. ${ }^{34}$ Selain itu, Rahimah, Rosnani dan Yuslaini juga telah membahaskan kurikulum bersepadu Islam dengan dua kriteria utama iaitu; 1) kepelbagaian mata pelajaran yang saling dihubungkan atau disepadukan berdasarkan kesatuan teori dan amalan praktikal di

Curriculum: Design and Implementation (Alexandria: Association for Supervision and Curriculum Development, 1989).

${ }^{30}$ G. Vars, Interdisciplinary Teaching in the Middle Grades (Columbus: National Middle School Association, 1987)

${ }^{31}$ Chris Jane Brough, "Implementing the democratic principles and practices of student centred curriculum integration in primary schools," The Curriculum Journal 23, no. 3 (2012): 345-369.

${ }^{32}$ L. K. Marcella, "Understanding Integrated Curriculum," The Curriculum Journal 9, no. 2 (1998): 197-209.

${ }^{33}$ L. K. Marcella, "Understanding Integrated Curriculum," 197-209.

${ }^{34}$ International Institute of Islamic Thought (IIIT), Integrated Curriculum (Final Report of Seminar on Islamic Thought and Contemporary Educational Issues for Senior Malaysian Educational Officers, International Institute of Islamic Thought, Herdon, 1989). 
dunia sebenar menerusi pengalaman atau penyertaan dalam aktiviti interaktif dan pembelajaran aktif; 2) kesepaduan ilmu perlu memberi peluang kepada pelajar bagi membangunkan pelbagai potensi diri dan kemahiran insaniah ${ }^{35}$. Berdasarkan kedua-dua konsep kurikulum bersepadu yang didatangkan ini membutkikan bahawa pendidikan holistik adalah matlamat dan tujuan utama pendidikan dalam landskap Islam bersesuaian dengan tuntutan kepada umat Islam supaya menguasai ilmu fardhu ain dan juga ilmu fardhu kifayah ${ }^{36}$.

Konsep integrasi kurikulum menurut sarjana Islam sepertimana yang dibahaskan di atas didapati bersesuaian untuk diaplikasikan dengan model integrasi kurikulum Robin Fogarty yang ciri modelnya menepati prinsip dan amalan pendidikan Islam. Model ini boleh dijadikan panduan kepada guru untuk diintegrasikan pendidikan alam sekitar dalam proses pengajaran dan pembelajaran di sekolah termasuklah pendidikan Islam.

Rajah 1: Model Integrasi Kurikulum Robin Fogarty, 1990

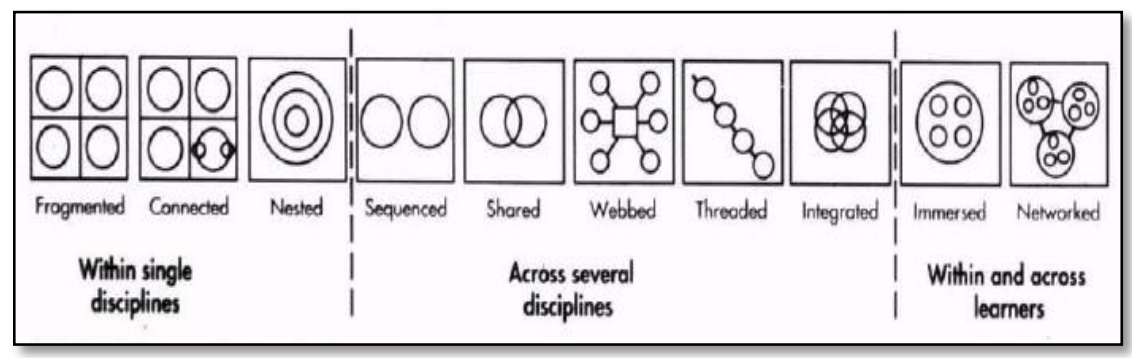

Robin Fogarty merupakan antara yang telah mencadangkan beberapa pendekatan dalam mengintegrasikan kurikulum secara teknikal. Menerusi bukunya, "The Mindful School: How to Integrate the Curriculum", terdapat 10 model atau cara untuk mengintegrasikan kurikulum. Kesemua model ini dikategorikan kepada tiga bahagian iaitu bahagian pertama; i) integrasi kurikulum dalam satu lapangan disiplin, model dalam bahagian ini

${ }^{35}$ Rahimah Embong et al., Islamic Integrated Curriculum (IIC) for the Transformation of Islamic Education System in Malaysia (Prosiding Seminar Kebangsaan Majlis Dekan Pendidikan IPTA kali ke-IV, 2013), 23-25.

${ }^{36}$ Rahimah Embong et al., Islamic Integrated Curriculum (IIC) for the Transformation of Islamic Education System in Malaysia, 23-25. 
adalah fragmented, connected dan nested. Bahagian kedua; ii) integrasi kurikulum merentasi beberapa lapangan disiplin yang lain, yang melibatkan lima model iaitu sequenced, shared, webbed, threaded dan integrated. Bahagian ketiga; iii) integrasi kurikulum yang merangkumkan bahagian pertama dan kedua dengan menekankan pembangunan pelajar secara menyeluruh. Dua model yang ditekankan iaitu immersed dan networked.

Berdasarkan rajah 1 di atas, amalan pengajaran dan pembelajaran yang bermakna dalam kalangan guru dan pelajar merupakan intisari penting menurut model integrasi kurikulum Robin Fogarty. Perkembangan kognitif, afektif serta psikomotor pelajar adalah pertimbangan yang perlu ditekankan oleh guru dalam model ini disamping pengukuhan pelbagai kemahiran seperti kemahiran metakognitif, kemahiran belajar dan kemahiran menyelesaikan masalah dalam landasan disiplin ilmu yang bervariasi $^{37}$.

Paradigma model ini merefleksikan bahawa sinergi guru perlu untuk saling bekerjasama bagi mengasimilasikan bidang dispilin masing-masing dalam proses pengintegrasian kurikulum di sekolah sekaligus menjustifikasikan peranan guru sebagai fasilitator dan pemudahcara bagi mewujudkan iklim pembelajaran aktif dalam kalangan pelajar ${ }^{38}$. Maksudnya di sini, pelajar membina pengetahuan dan idea mereka tanpa bergantung sepenuhnya kepada guru berdasarkan pengalaman dan penyertaan mereka dalam proses pengajaran dan pembelajaran yang diadakan di sekolah.

Selain itu, merujuk rajah 1 di atas juga, pemilihan pendekatan, kaedah dan strategi pengajaran guru perlu disesuaikan dengan cara mengintegrasikan kurikulum yang berfokuskan daripada satu lapangan disiplin sehinggalah yang lebih kompleks iaitu penyepaduan pelbagai bidang disiplin. Keadaan ini akan mempengaruhi minat dan kefahaman pelajar terhadap pengajaran konsep, prinsip, hukum dan lain-lain secara teori mahupun praktik. Oleh itu, jadual di bawah merupakan kupasan pendekatan integrasi kurikulum pendidikan Islam dengan pendidikan alam sekitar berdasarkan analisis model integrasi kurikulum Robin Fogarty

\footnotetext{
${ }^{37}$ L. K. Marcella, "Understanding integrated Curriculum," 197-209.

${ }^{38}$ R. Fogarty, "Ten ways to integrate curriculum," Educational Leadership 47, no. 2 (1991b): 61-5.
} 
yang selari dengan prinsip kurikulum bersepadu holistik menurut Islam.

Jadual 1: Analisis Pendekatan Integrasi Kurikulum

\begin{tabular}{|c|c|c|c|}
\hline$\overline{0}$ & $\frac{\overline{0}}{8}$ & Huraian & $\begin{array}{l}\text { Aplikasi pengintegrasian } \\
\text { pendidikan alam sekitar } \\
\text { dengan pendidikan Islam }\end{array}$ \\
\hline 1 & 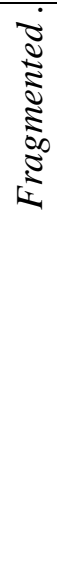 & $\begin{array}{l}\text { Satu bidang disiplin } \\
\text { ilmu } \\
\text { dihubungkan antara } \\
\text { satu sama lain untuk } \\
\text { difokuskan kefahaman } \\
\text { asas konsep. }\end{array}$ & $\begin{array}{l}\text { Unit akidah berteraskan } \\
\text { rukun Islam dalam bidang } \\
\text { akidah difokuskan kepada } \\
\text { pelajar tanpa mengaitkan } \\
\text { dengan mana-mana topik atau } \\
\text { bidang lain dalam pendidikan } \\
\text { Islam agar pelajar jelas } \\
\text { bahawa intipati atau konsep } \\
\text { rukun Islam itu berkait rapat } \\
\text { dengan peranannya sebagai } \\
\text { khalifah dan hamba Allah } \\
\text { dalam memakmurkan alam } \\
\text { sekitar. }\end{array}$ \\
\hline 2 & 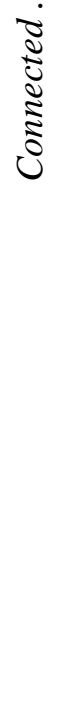 & $\begin{array}{l}\text { Topik-topik dalam satu } \\
\text { bidang disiplin ilmu } \\
\text { dihubungkan. }\end{array}$ & $\begin{array}{l}\text { Di bawah unit bersuci asas } \\
\text { kebersihan dalam pendidikan } \\
\text { Islam, topik konsep bersuci } \\
\text { dihubungkan dengan topik } \\
\text { wuduk yang mana masih di } \\
\text { bawah satu bidang iaitu } \\
\text { bidang ibadat tanpa } \\
\text { dihubungkan dengan bidang- } \\
\text { bidang pendidikan Islam yang } \\
\text { lain. Konsep bersuci yang } \\
\text { mungkin telah dipelajari oleh } \\
\text { pelajar dikaitkan dengan } \\
\text { amalan berjimat cermat } \\
\text { dalam mengunakan air untuk } \\
\text { berwuduk bagi menjamin } \\
\text { kelestarian alam sekitar. }\end{array}$ \\
\hline
\end{tabular}




\begin{tabular}{|c|c|c|c|}
\hline 3 & & $\begin{array}{l}\text { Kemahiran belajar, } \\
\text { sosial dan kemahiran } \\
\text { mengorganisasi idea } \\
\text { disasarkan bagi satu } \\
\text { unit atau topik } \\
\text { kandungan dalam satu } \\
\text { subjek sebagai usaha } \\
\text { untuk memahami } \\
\text { sepenuhnya disiplin } \\
\text { kandungan tersebut. } \\
\text { Dalam model ini, } \\
\text { kandungan kurikulum } \\
\text { masih kekal sebagai } \\
\text { tumpuan utama } \\
\text { pelajaran. }\end{array}$ & $\begin{array}{l}\text { Memfokuskan kepada satu } \\
\text { topik iaitu mengenai } \\
\text { kewujudan dan kebesaran } \\
\text { Allah di bawah bidang akidah } \\
\text { dan dihubungkan dengan } \\
\text { beberapa kemahiran belajar } \\
\text { dan kemahiran berfikir. Guru } \\
\text { menerapkan kemahiran } \\
\text { menyelesaikan masalah } \\
\text { kepada pelajar yang } \\
\text { merupakan salah satu } \\
\text { kemahiran berfikir mengenai } \\
\text { segala kejadian di muka bumi } \\
\text { ini adalah bukti kewujudan } \\
\text { Allah, tetapi kenapa masih } \\
\text { berlaku eksploitasi alam } \\
\text { sekitar secara rakus tanpa } \\
\text { henti. }\end{array}$ \\
\hline 4 & 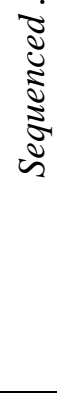 & $\begin{array}{l}\text { Dua bidang disiplin } \\
\text { ilmu iaitu dua subjek } \\
\text { saling berhubungan } \\
\text { antara satu sama lain } \\
\text { dalam memaknai } \\
\text { konsep, idea dan } \\
\text { kemahiran walaupun } \\
\text { subjek-subjek itu } \\
\text { terpisah atau terasing. }\end{array}$ & $\begin{array}{l}\text { Guru pendidikan Islam akan } \\
\text { menghubungkan mana-mana } \\
\text { intisari dalam semua bidang } \\
\text { pendidikan Islam dengan satu } \\
\text { subjek yang lain seperti sains } \\
\text { bagi menjelaskan konsep } \\
\text { alam sekitar menurut } \\
\text { pandangan Islam. }\end{array}$ \\
\hline
\end{tabular}




\begin{tabular}{|c|c|c|c|}
\hline & & 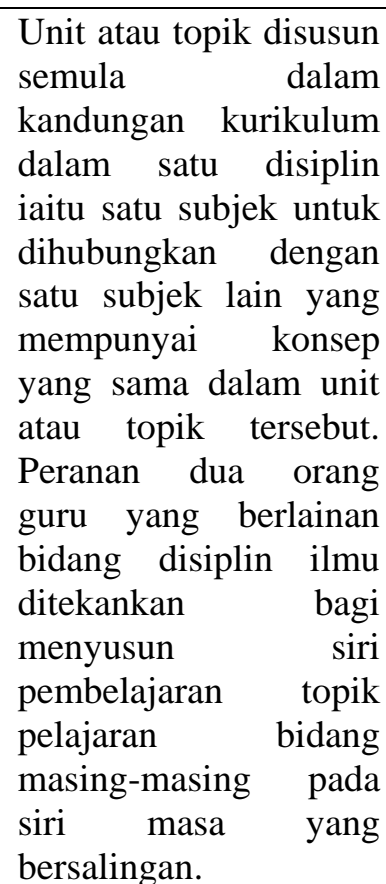 & $\begin{array}{l}\text { Topik adab kepada binatang } \\
\text { dalam pendidikan Islam serta } \\
\text { topik benda hidup dan benda } \\
\text { bukan hidup dalam subjek } \\
\text { sains diajar dalam minggu } \\
\text { yang sama supaya pelajar } \\
\text { dapat menghubungkan } \\
\text { konsep kedua-dua topik } \\
\text { tersebut menerusi beberapa } \\
\text { kemahiran yang diterapkan. } \\
\text { Guru pendidikan Islam dan } \\
\text { sains perlu berbincang bagi } \\
\text { menyusun topik-topik yang } \\
\text { berhubungan konsep dalam } \\
\text { rancangan pengajaran } \\
\text { tahunan (RPT). }\end{array}$ \\
\hline 6 & $\tau$ & $\begin{array}{l}\text { Penggunaan } \\
\text { pendekatan tematik } \\
\text { adalah asas pengajaran } \\
\text { bagi menspesifikasikan } \\
\text { konsep atau idea } \\
\text { berdasarkan tema yang } \\
\text { disasarkan. }\end{array}$ & $\begin{array}{l}\text { Tema alam sekitar akan diajar } \\
\text { dalam pendidikan Islam. } \\
\text { Maka guru akan } \\
\text { menghubungkan mana-mana } \\
\text { maklumat dalam bidang } \\
\text { pendidikan Islam itu sendiri } \\
\text { bagi menjelaskan konsep } \\
\text { hubungan alam sekitar dan } \\
\text { Islam secara spesifikasi dan } \\
\text { terperinci. }\end{array}$ \\
\hline
\end{tabular}




\begin{tabular}{|c|c|c|c|}
\hline 7 & & $\begin{array}{l}\text { Kemahiran berfikir, } \\
\text { kemahiran sosial, } \\
\text { kecerdasan pelbagai } \\
\text { dan kemahiran belajar } \\
\text { adalah di bawah satu } \\
\text { jalur keperluan seluruh } \\
\text { jaringan bagi pelbagai } \\
\text { disiplin ilmu tanpa } \\
\text { mengasingkan antara } \\
\text { kemahiran-kemahiran } \\
\text { tersebut dengan bidang } \\
\text { disiplin yang lain. }\end{array}$ & $\begin{array}{l}\text { Kemahiran } \\
\text { dibangunkan dengan pelbagar } \\
\text { pendekatan akan diajar dalam } \\
\text { pendidikan Islam tentang } \\
\text { bagaimana cara yang } \\
\text { digalakkan oleh Islam bagi } \\
\text { memelihara dan memulihara } \\
\text { alam sekitar termasuklah } \\
\text { penggunaan teknologi dan } \\
\text { pertimbangan alternatif lain. } \\
\text { Situasi ini akan } \\
\text { menghidupkan } \\
\text { pembelajaran bermakna } \\
\text { kepada pelajar. }\end{array}$ \\
\hline 8 & 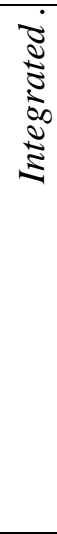 & $\begin{array}{l}\text { Sekumpulan guru } \\
\text { saling bekerjasama } \\
\text { dalam bidang masing- } \\
\text { masing bagi mencari } \\
\text { pertindihan konsep dan } \\
\text { idea-idea dalam subjek } \\
\text { yang mereka ajar. Hal } \\
\text { ini supaya mereka } \\
\text { dapat merancang unit } \\
\text { pengajaran sekaligus } \\
\text { melaksanakannya } \\
\text { dalam kelas. }\end{array}$ & $\begin{array}{l}\text { Guru pendidikan Islam dan } \\
\text { pelbagai guru dari berbeza } \\
\text { opsyen berbincang mengenai } \\
\text { mana-mana persamaan } \\
\text { konsep atau nilai eko-etika } \\
\text { Islam yang terdapat pada } \\
\text { dalam subjek yang mereka } \\
\text { ajar. Hal ini akan } \\
\text { mendedahkan kepada pelajar } \\
\text { mengenai penjagaan alam } \\
\text { sekitar yang meluas dalam } \\
\text { segenap aspek kehidupan. }\end{array}$ \\
\hline 99 & 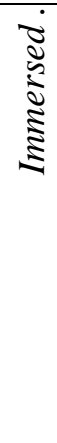 & $\begin{array}{l}\text { Pelajar } \\
\text { bertanggungjawab } \\
\text { terhadap integrasi } \\
\text { bidang ilmu yang } \\
\text { diminati. Pelajar } \\
\text { menyaringkan } \\
\text { maklumat berdasarkan } \\
\text { lensa mereka sendiri. }\end{array}$ & $\begin{array}{l}\text { Pelajar akan merasakan satu } \\
\text { kepentigan menghubungkan } \\
\text { komponen alam sekitar } \\
\text { dengan subjek pendidikan } \\
\text { Islam berdasarkan strategi } \\
\text { yang sesuai. Mereka akan } \\
\text { berkongsi maklumat dengan } \\
\text { rakan yang lain bagi } \\
\text { memahami konsep } \\
\text { perhubungan tersebut. }\end{array}$ \\
\hline
\end{tabular}




\begin{tabular}{|c|c|c|c|}
\hline 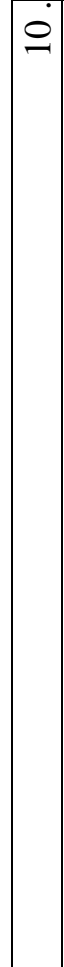 & $\begin{array}{l}\text { J } \\
\frac{\pi}{3} \\
\text { j } \\
\text { d } \\
z\end{array}$ & $\begin{array}{l}\text { Pelajar mengarah } \\
\text { secara langsung proses } \\
\text { integrasi dengan } \\
\text { didedahkan pelbagai } \\
\text { rangkaian sumber dan } \\
\text { pakar mengenai selok } \\
\text { belok dan dimensi } \\
\text { pelbagai bidang atau } \\
\text { sesuatu disiplin ilmu. }\end{array}$ & $\begin{array}{l}\text { Pelajar akan didedahkan } \\
\text { dengan pelbagai sumber } \\
\text { semasa proses integrasi } \\
\text { pengajaran pendidikan Islam } \\
\text { dengan pendidikan alam } \\
\text { sekitar di sekolah dan dalam } \\
\text { masa yang sama maklumat } \\
\text { integrasi konsep yang mereka } \\
\text { perolehi tersebut akan } \\
\text { disahkan oleh guru-guru yang } \\
\text { lain bukan setakat daripada } \\
\text { guru pendidikan Islam sahaja. } \\
\text { Daripada itu beberapa aspek } \\
\text { psikologi pelajar akan turut } \\
\text { dibangunkan seperti } \\
\text { kemahiran membuat } \\
\text { keputusan yang betul, } \\
\text { bersikap dan bertindak positif } \\
\text { terhadap alam sekitar serta } \\
\text { terlibat dengan usaha } \\
\text { melestarikannya berdasarkan } \\
\text { nilai-nilai yang diterapkan. }\end{array}$ \\
\hline
\end{tabular}

Pendidikan Islam dengan Pendidikan Alam Sekitar

Berdasarkan jadual 1 di atas, keserasian model integrasi kurikulum Robin Forgaty dengan konsep kesepaduan ilmu menurut pandangan Islam adalah kedua-duanya menjurus kepada pendidikan holistik. Justeru, model Robin Fogarty merupakan salah satu model pendidikan kurikulum yang boleh diadaptasikan dalam menyepadukan pendidikan alam sekitar dengan pendidikan Islam bagi memperkasakan nilai eko-etika Islam di sekolah.

\section{Penutup}

Penyepaduan pendidikan Islam dengan pendidikan alam sekitar di sekolah perlu dilestarikan dengan satu kerangka yang jelas iaitu berasaskan ketauhidan atau rabbani. Menyaksikan potensi pengintegrasian kedua-dua pendidikan tersebut sepertimana yang dibahaskan sebelum ini, adalah tidak mustahil pemerkasaan nilai eko-etika Islam di sekolah akan dapat dicapai secara optimum. Hal 
ini melihat pada pertimbangan terhadap pembangunan akhlak pelajar menerusi medium pendidikan ini yang akan memacu hasrat keseimbangan dan kemampanan hidup seperti yang diingini. Pengaplikasian model integrasi kurikulum Robin Fogarty terhadap proses penyepaduan ini menyarankan pendekatan dan strategi guru yang fleksibel dalam membentuk iklim penghayatan nilai ekoetika Islam dalam bilik darjah. Adapun cadangan model Robin Fogarty ini diadaptasikan agar sekurang-kurangnya operasional penyepaduan pendidikan Islam dengan pendidikan alam sekitar bukanlah retorik semata-mata apatah lagi bersifat atrifisial dan juga superfisial iaitu sekadar melepaskan batuk di tangga. Dengan adanya cadangan adaptasi model tersebut, guru dan pelajar akan lebih jelas mengenai kaedah dan teknik proses penyepaduan kurikulum yang seharusnya itu berlangsung di sekolah. Oleh itu, pendidikan holistik yang merupakan aspirasi negara perlu direalisasikan oleh semua pihak agar kelangsungan hidup lebih tersusun dan terancang ke arah pembangunan tamadun dan bangsa Malaysia lestari.

\section{Bibliografi}

A. Abedi-Sarvestani, et al., "Essence And Outlooks Of Environmental Ethics With Emphasis On Islamic Perspective," Iranian Journal of Ethics in Science and Technology 2, no. 1 (2007): 59-72.

A. M. Schwencke. Globalized Eco-Islam: A Survey of Global Islamic Environmentalism. Leiden University, Leiden Institute for Religious Studies (LIRS), 2012.

Brough, Chris Jane. "Implementing The Democratic Principles And Practices Of Student Centred Curriculum Integration In Primary Schools". The Curriculum Journal 23, no. 3 (2012): 345-369.

Drake, S. Planning Integrated Curriculum: The Call to Adventure. Alexandria: Association for Supervision and Curriculum Development, 1993.

Ekpenyong Obo Ekpenyong. "Islam and Global Ecological Crisis: An Eco-Theological Review". International Journal of Asian Social Science 7, no. 3 (2013): 591-1594 
Fachruddin Majeri Mangunjaya, "Developing Environmental Awareness and Conservation through Islamic Teaching," Journal of Islamic Studies 22, no. 1 (2011): 36-49

Fachruddin Majeri Mangunjaya. "Developing Environmental Awareness and Conservation through Islamic Teaching". Journal of Islamic Studies 22, no. 22 (2011): 36-49.

H. Jacobs. ed. Interdisciplinary Curriculum: Design and Implementation. Alexandria: Association for Supervision and Curriculum Development, 1989.

Habibah Lateh dan Punitha Muniandy. "Amalan Pengajaran Pendidikan Alam Sekitar di Institut Pendidikan Guru, Kampus Pulau Pinang". Malaysia Journal of Society and Space 2, no. 2 (2012):1-6.

Hazura Abu Bakar. "Hubungan Antara Penghayatan Agama, Nilai Hidup dan Pengetahuan Alam Sekitar Pelajar Muslim degan Sikap dan Tingkah Laku". Tesis kedoktoran, Universiti Sains Malaysia, 2009.

Helen Kopnina dan Frans Meijers, "Education for Sustainable Development (ESD)". International Journal of Sustainability in Higher Education 15, no. 2 (2014): 188-207.

Ho Yuek Ming \& Azizi Muda, Assessment of Pre-Service Teachers' Environmental Citizenship Attributes: Implications for Environmental Education Curriculum and Training (3rd International Conference on Science and Mathematics Education (COSMEd), Pulau Pinang, 2009), 1-5.

Ibrahim Abu Bakar. "Islamic Theological Teachings on Ecology". International Journal of Business and Social Science 3, no. 13 (July 2012): 222-226

International Institute of Islamic Thought (IIIT), Integrated Curriculum (Final Report of Seminar on Islamic Thought and Contemporary Educational Issues for Senior Malaysian Educational Officers, International Institute of Islamic Thought, Herdon, 1989.

Kementerian Pendidikan Malaysia, Pelan Pembangunan Pendidikan Malaysia 2013-2025: Pendidikan Prasekolah hingga Lepas Menengah. Putrajaya: Kementerian Pendidikan Malaysia, 2013.

M. S. Aini et al., "Impact of Environmental Education on Concern, Knowledge and Sustainable Behavior of Primary 
School Children". Health and the Environment Journal 2, no. 1 (2011). 50-53.

Maria Salih dan Hazinah Nor Hanipah. Penerapan Pendidikan Alam Sekitar Merentas Kurikulum di Kalangan Guru Sekolah Menengah: Satu Tinjauan, laporan akhir penyelidikan. Universiti Pendidikan Sultan Idris, 2009.

Mohamed, Najma. Revitalising an Eco-Justice Ethics of Islam: by Way of Environmental Education: Implications for Islamic Education, 86-131; S.H. Nasr, Man and Nature: the Spiritual Crisis of Modern Man (New Edition Chicago, ABC International Group, 1997); S.H. Nasr, Religion and the Order of Nature. New York Oxford: Oxford University Press, 1996.

Mohd Istajib Mokhtar dan Raihanah Abdullah. "Islamic Environmental Jurisprudence and Conservation Practices in Malaysia". Journal of Dharma 39, no. 2 (2014): 7-22

Najma Mohamed, Revitalising an Eco-Justice Ethics of Islam: by Way of Environmental Education: Implications for Islamic Education. Tesis kedoktoran, South Africa, Stellenbosch University, 2012.

Nurul Hidayah et al.,"Pengetahuan Murid dan Perkaitan Ibu Bapa Terhadap Kesedaran Alam," Jurnal Teknologi 1 (2013): 51-57.

Othman Talib. Zero Draft of Thesis: Teknik Efisien Penulisan Tesis dengan Navigation Pane/Document Map dan Mandeley. Selangor: MPWS Rich Resources, 2014).35.

Pusat Perkembangan Kurikulum, Buku Panduan Guru Pendidikan Alam Sekitar Merentas Kurikulum KBSM. Pusat Perkembangan Kurikulum, Kementerian Pendidikan Malaysia, 1999.

R. Fogarty, "Ten Ways To Integrate Curriculum". Educational Leadership 47, no. 2 (1991b): 61-5.

Rahimah Embong et al., Islamic Integrated Curriculum (IIC) for the Transformation of Islamic Education System in Malaysia. Prosiding Seminar Kebangsaan Majlis Dekan Pendidikan IPTA kali ke-IV, 2013.

Vars, G. Interdisciplinary Teaching in the Middle Grades. Columbus: National Middle School Association, 1987.

Yahaya Jusoh dan Azhar Muhammad. Falsafah Ilmu dalam AlQuran: Ontologi, Epistemologi dan Aksiologi. Skudai: Universiti Teknologi Malaysia, 2012. 
Yahaya Jusoh dan Azhar Muhammad. Pendidikan Falsafah Sains al-Quran. Skudai: Universiti Teknologi Malaysia, 2007.

Zaini Ujang. Minda Lestari: Pembangunan Negara dan Pemuliharaan Alam Sekitar. Johor Bahru: UTM Press, 2009.

Zarrintaj Aminrad et al., "Environmental Education in Malaysia, Progresses and Challenges Ahead", Life Science Journal 9, no. 2 (2012): 1149-1154. 
Aziz, Sarina dan Yusmini, Pengintegrasian Pendidikan Islam 